\title{
Desempenho produtivo de híbridos de milho em função de doses de nitrogênio aplicado em cobertura
}

\section{Productive performance of corn hybrids in the function of nitrogen doses applied in topdressing}

\author{
Rogério Farinelli ${ }^{1}$, Vagner Rodolfo Pereira Matareli ${ }^{1}$, Everson Diego de Souza ${ }^{1}$ \\ ${ }^{1}$ Centro Universitário da Fundação Educacional de Barretos (UNIFEB) - Barretos (SP), Brasil.
}

\begin{abstract}
Resumo
Segundo pesquisas e trabalhos científicos, há resultados que afirmam que mesmo quando semeado em sucessão à soja, o milho pode ter sua produtividade aumentada com a adubação nitrogenada em cobertura. Dessa forma, o objetivo do trabalho foi avaliar o efeito de doses de nitrogênio $(\mathrm{N})$ em cobertura no milho safrinha, cultivado com preparo convencional do solo em sucessão à cultura da soja. O delineamento experimental foi de blocos ao acaso em esquema fatorial $4 \times 2$, com quatro repetições. Os tratamentos foram dois híbridos de milho (BM 207 - convencional e DKB 390 PRO2 - transgênico) e quatro doses de N em cobertura $\left(0,30,60\right.$ e $\left.90 \mathrm{~kg} \mathrm{ha}^{-1}\right)$, com fonte ureia e aplicação no estádio $\mathrm{V}_{8}$. A adubação nitrogenada influenciou positivamente na formação das raízes, massa de 100 grãos e produtividade de grãos. O híbrido BM 207 não respondeu às doses crescentes de $\mathrm{N}$, enquanto a resposta foi quadrática ao híbrido DKB 390 PRO2, com maior produtividade de grãos obtida na dose de $74,4 \mathrm{~kg} \mathrm{ha}^{-1}$. Os maiores incrementos e ganhos significativos de grãos foram estabelecidos para o híbrido DKB 390 PRO2 em relação às doses de $\mathrm{N}$ aplicadas, quando comparado ao BM 207.
\end{abstract}

Palavras-chave: safrinha; adubação nitrogenada; genótipos; produtividade; eficiência agronômica.

\begin{abstract}
According to research and scientific work, there are results affirming that even when corn yield can be increased nitrogen fertilization in topdressing even when sown in succession to soybean. The experimental design was randomized blocks arranged $4 \times 2$ factorial with 4 repetitions. The treatments consisted of two corn hybrids (BM 207 - conventional and DKB 390 PRO2 - GM) and four doses of nitrogen topdressing $\left(0,30,60\right.$ and $\left.90 \mathrm{~kg} \mathrm{ha}^{-1}\right)$, supply urea applied at V8 stadium. Nitrogen fertilization positively influenced the root formation, 100 grains weight and grain yield. The BM 207 hybrid did not respond to increasing $\mathrm{N}$ doses, while the response was quadratic for DKB $390 \mathrm{PRO}$, and the highest grain yield was obtained with $74.4 \mathrm{~kg} \mathrm{ha}^{-1}$. The highest increase, and most significant gain in grain yield was established for hybrid DKB 390 PRO2 regarding N doses when compared to BM 207.
\end{abstract}

Keywords: second season; nitrogen fertilization; genotypes; yield; agronomic efficiency.

\footnotetext{
Autor para correspondência: Rogério Farinelli - Centro Universitário da Fundação Educacional de Barretos (UNIFEB) - Avenida Professor Frade Monte, 389 - CEP: 14783-226 - Barretos (SP), Brasil E-mail: rogerio.farinelli@unifeb.edu.br
}

Recebido em: 25 de outubro de 2017

Aceito para publicação em: 05 de novembro de 2017 


\section{Introdução}

O cultivo do milho safrinha tem sido viável economicamente para o produtor rural, pois, além do retorno financeiro, proporciona benefícios agronômicos da rotação de culturas, como: 0 aumento da palhada, fundamental para a manutenção do sistema de plantio direto, o controle de pragas e doenças da lavoura de verão. Ademais, a sucessão de cultivos distintos também contribui para manter o equilíbrio dos nutrientes no solo e aumentar a sua fertilidade, assim como permitir melhor utilização dos insumos agrícolas.

O milho é uma cultura extremamente eficiente na conversão de energia luminosa em biomassa, apresentando elevada exigência nutricional. Portanto, o manejo da nutrição é um dos fatores preponderantes no aumento de produtividade de grãos (FORNASIERI FILHO, 2007). O nutriente que merece maior atenção, e também por ser o mais exigido, é, sem dúvida, o nitrogênio $(\mathrm{N})$, pois afeta diretamente a produtividade da cultura. Trata-se de um elemento extremamente dinâmico no ambiente e que recebe bastante influência do tipo de manejo adotado, mas que necessita de mais estudos sobre o efeito de suas doses e épocas de aplicação. As recomendações da adubação nitrogenada em cobertura em cultivo de sequeiro variam de 50 a $90 \mathrm{~kg} \mathrm{ha}^{-1}$ de $\mathrm{N}$, para altas produtividades e de 120 a $200 \mathrm{~kg} \mathrm{ha}^{-1}$, para cultivo irrigado (FARINELLI; LEMOS, 2010; SOUZA et al., 2012).

Estudos sugerem que, mesmo quando semeado em sucessão à soja, o milho safrinha pode ter sua produtividade aumentada com a adubação nitrogenada em cobertura. No entanto, ainda existem dúvidas sobre qual a melhor fonte e dose de N para a cultura nessa modalidade de cultivo.

Avaliando diferentes doses e épocas de aplicação de $\mathrm{N}$ no cultivo de milho safrinha, Mar et al. (2003) obtiveram os melhores resultados com produtividade acima de $6 \mathrm{mil} \mathrm{kg} \mathrm{ha}^{-1}$, utilizando doses entre 90 e $120 \mathrm{~kg} \mathrm{ha}^{-1}$ do nutriente, com aplicação de $1 / 3$ na semeadura e $2 / 3$ em cobertura quando as plantas apresentavam de quatro a oito folhas totalmente expandidas.

No trabalho realizado por Kappes et al. (2009), a produtividade de grãos acima de $6 \mathrm{mil} \mathrm{kg} \mathrm{ha}^{-1}$ no milho safrinha cultivado em sucessão à soja foi alcançada pela aplicação de $\mathrm{N}$ em cobertura no estádio $\mathrm{V}_{10}$ (dez folhas completamente expandidas), não havendo interação significativa entre época e fonte utilizada. Resultado semelhante foi obtido por Souza et al. (2006), que constataram aumento de $22,1 \%$ na produtividade em relação à testemunha pela aplicação de $120 \mathrm{~kg} \mathrm{ha}^{-1}$ de N.

Soratto et al. (2010) concluíram que a aplicação de nitrogênio em cobertura $\left(0,30,60\right.$ e $\left.120 \mathrm{~kg} \mathrm{ha}^{-1}\right)$ aumentou os teores do nitrogênio e enxofre na folha, altura da planta, diâmetro do colmo, número de espigas por planta e grãos por espiga, massa de mil grãos e produtividade de grãos do milho safrinha, em sucessão à soja, independentemente da fonte utilizada.

Em outro estudo, não ocorreu influência de fontes e formas de parcelamento do $\mathrm{N}$ no milho safrinha, cultivado após a soja no sistema de plantio direto. Também se verificou que a produtividade de grãos variou de $4.877 \mathrm{~kg} \mathrm{ha}^{-1}$ na testemunha a $5.347 \mathrm{~kg} \mathrm{ha}^{-1}$ com a aplicação de $90 \mathrm{~kg} \mathrm{ha}^{-1} \mathrm{de}$ N (SORATTO et al., 2012).

No cultivo em sucessão ao milho safra, Souza et al. (2012) afirmaram que o incremento das doses de nitrogênio aumentou a produtividade de grãos de milho safrinha até a dose de $150 \mathrm{~kg} \mathrm{ha}^{-1} \mathrm{de} \mathrm{N}$, em média, independentemente da época de aplicação e da fonte de N.

Já Góes et al. (2012) relataram em seu trabalho que, para a produtividade de grãos, não houve efeito de fontes e doses de nitrogênio $\left(0,20,40,60\right.$ e $\left.80 \mathrm{~kg} \mathrm{ha}^{-1}\right)$ para o milho safrinha quando semeado em área de pousio. A resposta da produtividade à adubação nitrogenada em cobertura depende de vários fatores, como umidade do solo, genética da planta e dose utilizada.

$\mathrm{O}$ suprimento de $\mathrm{N}$ na cultura do milho é um fator extremamente importante ao sucesso do cultivo do grão, exigindo conhecimentos quanto a melhor forma de manejo diante de uma série de condições encontradas. Em se tratando de milho safrinha, quando cultivado em sucessão à soja, a aplicação de nitrogênio proporciona incrementos satisfatórios de produtividade. No entanto, a definição da dose adequada e da melhor época de aplicação de $\mathrm{N}$ em cobertura deve ser mais bem estabelecida, principalmente nesse sistema de produção.

Sendo assim, o objetivo do trabalho de pesquisa foi avaliar o efeito de doses de nitrogênio em cobertura no desempenho agronômico de dois híbridos de milho cultivados na safrinha em sucessão à soja. 


\section{Material e Métodos}

$\mathrm{O}$ experimento foi instalado e conduzido, durante a safrinha de 2015, em Colina (SP), em um solo classificado como Latossolo vermelho distrófico, apresentando latitude de $20^{\circ} 45^{\prime} \mathrm{S}$, longitude de $48^{\circ} 36^{\prime} \mathrm{O}$ e 530 metros de altitude. Segundo a classificação de Köeppen, o clima da região é do tipo Cwa, sendo definido como tropical de altitude, com inverno seco, verão quente e chuvoso, obtendo uma precipitação de $555 \mathrm{~mm}$ durante todo o ciclo da cultura, com média de $5,4 \mathrm{~mm}$ por dia.

O milho foi cultivado em área em que, anteriormente, houve o cultivo da soja. Antes da instalação da cultura do milho, foi realizada uma análise de solo, conforme a Tabela 1 .

O preparo do solo foi realizado com a utilização de gradagem intermediária a fim de incorporar os restos culturais, com posterior gradagem niveladora para destorroar e nivelar o solo da área experimental. A semeadura foi efetuada mecanicamente em 26 de março de 2015 , no período de cultivo de safrinha para a região norte/nordeste do Estado de São Paulo, utilizando o espaçamento de $0,90 \mathrm{~m}$ entre as linhas, distribuindo 4,5 sementes por metro, para uma população inicial de 50 mil plantas ha-1 ${ }^{-1}$.

A adubação mineral de semeadura foi de $165 \mathrm{~kg} \mathrm{ha}^{-1}$ do formulado 4-14-8 +0,5\% $\mathrm{Zn}$, sendo fornecidos $6,6 \mathrm{~kg} \mathrm{ha}^{-1}$ de N, 23,1 $\mathrm{kg} \mathrm{ha}^{-1}$ de $\mathrm{P}_{2} \mathrm{O}_{5}$ e $13,2 \mathrm{~kg} \mathrm{ha}^{-1}$ de $\mathrm{K}_{2} \mathrm{O}+0,825 \mathrm{~kg} \mathrm{ha}^{-1}$ de $\mathrm{Zn}$, levando-se em consideração os resultados da análise química do solo e algumas recomendações técnicas, como a textura do solo, a profundidade da análise do solo e a estimativa de produtividade.

O delineamento experimental foi de blocos ao acaso em esquema fatorial $4 \times 2$, constituindo-se de oito tratamentos com quatro repetições. Os tratamentos ocorreram em dois híbridos de milho (BM 207 convencional e DKB 390 PRO2 - transgênico), com quatro doses de $\mathrm{N}$, sendo $0,30,60$ e $90 \mathrm{~kg} \mathrm{ha}^{-1}$. A aplicação das doses em cobertura foi realizada no estádio fenológico $\mathrm{V}_{8}$ (oito folhas totalmente expandidas) em filete contínuo a $10 \mathrm{~cm}$ de distância das plantas de milho. O fertilizante utilizado foi a ureia, contendo $45 \%$ de N. Cada parcela foi composta por quatro linhas de $5 \mathrm{~m}$ de comprimento, com $1 \mathrm{~m}$ entre as parcelas, considerando para área útil as duas linhas centrais, desprezando-se $0,50 \mathrm{~m}$ de cada extremidade.

O híbrido BMX 207 é convencional e pertence à empresa Biomatrix. Possui como características: ciclo precoce, porte alto, empalhamento ótimo, grãos semiduros e vermelho-alaranjados, com finalidade de produção de grãos. O híbrido DKB $390 \mathrm{PRO} 2$ pertence à empresa Dekalb-Monsanto. Possui como características: ciclo precoce, porte alto, empalhamento bom, grãos duros e amarelo-alaranjados, com finalidade de produção de grãos. Além de apresentar duas resistências: a primeira às lagartas (do cartucho, da espiga e broca do colmo) e a segunda ao glifosato.

No florescimento feminino (estádio R2) em dez plantas ao acaso por parcela, foi determinada a área foliar na folha acima e oposta da primeira espiga, utilizando os parâmetros de comprimento máximo do limbo (C), a largura máxima perpendicular à nervura principal do limbo foliar (L) e o produto do comprimento pela largura e por um fator de correção de $0,75(\mathrm{AF}=\mathrm{CxLx} 0,75)$. Também foi avaliado o número de folhas acima da primeira espiga, bem como a matéria seca do sistema radicular, sendo definida como a fitomassa seca de todo o sistema radicular, depois de secagem em estufa por $60-70{ }^{\circ} \mathrm{C}$ com circulação de ar forçada por 72 horas.

Por ocasião da maturidade fisiológica dos grãos (estádio $\mathrm{R}_{6}$ ), foram determinadas dez plantas ao acaso pela altura de planta, medindo-se a distância entre o colo da planta e a inserção do pendão, e pela altura de inserção da primeira espiga, medindo-se a distância entre o colo da planta e a inserção da primeira espiga e o diâmetro de colmo, utilizando

Tabela 1. Atributos químicos do solo da área experimental.

\begin{tabular}{|c|c|c|c|c|c|c|c|c|c|}
\hline Profundidade $(\mathrm{cm})$ & pH & $\mathbf{P}$ & $\mathbf{K}$ & $\mathbf{C a}$ & Mg & Al & $\mathbf{H}+\mathbf{A l}$ & $\mathbf{N a}$ & SB \\
\hline $\mathbf{c m}$ & \multicolumn{3}{|c|}{$\mathrm{mg} / \mathrm{dm}^{3}$} & \multicolumn{6}{|c|}{ 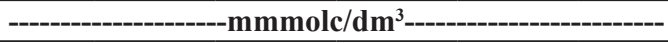 } \\
\hline $0-20$ & 5,8 & 7,2 & 0,8 & 23,6 & 14,9 & 0,0 & 14,1 & 0,0 & 39,3 \\
\hline Profundidade & $\mathbf{V}$ & $\mathbf{F e}$ & $\mathbf{C u}$ & $\mathbf{Z n}$ & Mn & $\mathbf{S}$ & B & MO & $\mathrm{CO}$ \\
\hline$(\mathrm{cm})$ & $\%$ & \multicolumn{6}{|c|}{ 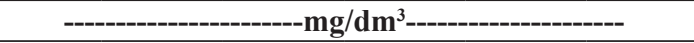 } & \multicolumn{2}{|c|}{----g/dm³--- } \\
\hline $0-20$ & 73,5 & 6,8 & 0,6 & 5,1 & 11,0 & 14,6 & 0,2 & 16,6 & 10,0 \\
\hline
\end{tabular}


um paquímetro no segundo entrenó acima da superfície do solo.

Antes da colheita, também em dez plantas ao acaso por parcela, foram avaliados o número de fileiras, o número de grãos por espiga e a massa de 100 grãos, sendo esta mediante duas amostras de 100 grãos de milho, com posterior pesagem e correção da umidade a $13 \%$ de base úmida. A produtividade de grãos foi obtida por meio do processo de trilha das espigas contidas na área útil da parcela, determinando-se o teor de água calculado em $13 \%$ de base úmida.

Também se determinou a eficiência agronômica de uso de nitrogênio, calculada utilizando-se a fórmula $\mathrm{EA}=(\mathrm{PGcf}-\mathrm{Gsf}) /(\mathrm{QNa})$, expressa em $\mathrm{kg} \mathrm{kg}^{-1}$, em que: PGcf é a produção de grãos com fertilizante nitrogenado; PGsf, a produção de grãos sem fertilizante nitrogenado; e QNa, a quantidade de nitrogênio aplicado (em kg) (FAGERIA; BALIGAR, 2005).

Os dados foram analisados pelo teste $\mathrm{F}$, com os valores obtidos pelos híbridos comparados pelo teste de Tukey a $5 \%$ de probabilidade, enquanto os valores para as doses de $\mathrm{N}$ em cobertura e também as interações significativas foram avaliados por análise de regressão polinomial. Para essas análises foi empregado o programa estatístico SISVAR (FERREIRA, 2011).

\section{Resultados e Discussão}

Em relação à área foliar, não houve efeito significativo quanto às doses de $\mathrm{N}$ em cobertura, ocorrendo diferença entre híbridos, com o DKB 390 PRO2 tendo maior área foliar do que o BM 207 (Tabela 2). Isso se explica devido ao híbridos DKB 390 PRO2 possuir uma transgenia de duas proteínas Bt com modos de ação diferentes. Elas auxiliam no manejo das principais pragas que atacam a cultura do milho, como as lagartas do cartucho, da espiga e a broca do colmo, fazendo com que as plantas cresçam sem nenhum dano nas suas partes aéreas, e proporcionando maior área foliar. Os resultados obtidos nesse experimento não se assemelham ao trabalho de Amaral Filho et al. (2005), no qual afirmam que a adubação nitrogenada influenciou $\mathrm{a}$ área foliar, pois o $\mathrm{N}$ favorece maior crescimento vegetativo, mostrando um efeito positivo sobre o índice da área foliar.

No que se refere às folhas acima da espiga, também não ocorreu diferença significativa em relação às doses de $\mathrm{N}$ aplicado. Houve apenas diferença significativa a 5\%, em comparação aos híbridos, no qual o DKB 390 PRO2 teve um maior número de folhas acima da primeira espiga (Tabela 2). O maior número de folhas acima da espiga associado à maior área foliar propicia aos híbridos modernos, como o DKB PRO2, maior

Tabela 2. Área foliar e número de folhas acima da espiga em função de doses de $\mathrm{N}$ em cobertura em dois híbridos de milho na safrinha.

\begin{tabular}{ccc}
\hline Tratamentos & $\begin{array}{c}\text { Área foliar } \\
\left(\mathbf{c m}^{2}\right)\end{array}$ & $\begin{array}{c}\text { Folhas acima da espiga } \\
\left(\mathbf{n}^{\mathbf{0}}\right)\end{array}$ \\
\hline Doses de N em cobertura (D) & & 5,6 \\
0 & 499,7 & 5,8 \\
60 & 540,9 & 5,9 \\
90 & 542,5 & 6,0 \\
Teste F & 577,8 & $1,06^{\text {ns }}$ \\
CV (\%) & $0,81^{\text {ns }}$ & 3,32 \\
\hline Híbridos (H) & 6,13 & \\
\hline BM 207 & $464,8 \mathrm{~b}$ & $5,6 \mathrm{~b}$ \\
DKB 390 PRO2 & $615,5 \mathrm{a}$ & $6,0 \mathrm{a}$ \\
Teste F & $18,20^{*}$ & $11,20^{*}$ \\
CV (\%) & 18,51 & 6,59 \\
\hline D x H & & \\
\hline Teste F & $4,34^{\text {ns }}$ & $0,55^{\text {ns }}$ \\
Média & 540,2 & 5,8 \\
\hline
\end{tabular}

Médias seguidas de letras distintas diferem entre si pelo teste de Tukey a $5 \%$ de probabilidade. **significativo a $1 \%$,

${ }^{*}$ significativo a $5 \% \mathrm{e}^{\mathrm{ns}}$ não significativo. 
captação da energia luminosa, pois em torno de $75 \%$ da radiação solar convertida no processo fotossintético para a formação da espiga provém das folhas superiores da planta (RITCHIE et al., 2003).

Para a característica agronômica matéria seca do sistema radicular, ocorreu diferença significativa quanto às doses de $\mathrm{N}$ aplicado, obtendo acréscimo linear nos valores, com a dose de $90 \mathrm{~kg} \mathrm{ha}^{-1} \mathrm{de} \mathrm{N}$ promovendo 212,3 $\mathrm{g} \mathrm{planta}^{-1}$. Isso demonstra que o $\mathrm{N}$ influencia não só o crescimento vegetativo, mas também o sistema radicular, por isso é o elemento mais requerido pelo milho. Em relação aos híbridos, não ocorreu diferença significativa, com valores bem próximos, podendo-se afirmar que o nitrogênio não influenciou o crescimento radicular de nenhum dos materiais semeados (Tabela 3).

Para a altura de planta e da primeira espiga, não ocorreu efeito das doses de $\mathrm{N}$ em cobertura. À medida que se aumentaram as doses de $\mathrm{N}$, não aconteceu nenhum aumento linear concomitante nas alturas avaliadas. Em relação aos híbridos de milho, de acordo com o teste de Tukey, houve diferença significativa entre o tamanho da planta e a altura da espiga dos híbridos. Isso se explica devido ao melhoramento genético do híbrido e à sua resposta à adubação nitrogenada, observados no DBK 390 PRO2, com uma diferença de altura de aproximadamente $30 \mathrm{~cm} \mathrm{e} 24 \mathrm{~cm}$, para a planta e para a inserção da espiga, respectivamente (Tabela 3).

Em relação ao trabalho de Mar et al. (2003), os resultados obtidos no experimento não se assemelharam, pois foi verificado um aumento da altura de plantas e de inserção da espiga do milho safrinha, em sucessão à soja, em resposta à aplicação de $\mathrm{N}$ em cobertura. Houve diferença entre fontes apenas com a aplicação de $120 \mathrm{~kg} \mathrm{ha}^{-1}$ de $\mathrm{N}$ em cobertura, mas o sulfato de amônio proporcionou valor superior à ureia, de $0,12 \mathrm{~m}$, tanto para altura de planta quanto para de inserção da primeira espiga.

Para Casagrande \& Fornasieri Filho (2002), maiores alturas de inserção das espigas e da planta podem predispor a planta ao acamamento ou quebramento, fatores que não foram observados no experimento, provavelmente pelo fato de os híbridos utilizados não serem suscetíveis a essas características indesejáveis (CRUZ; PEREIRA FILHO; SILVA, 2013).

Para o diâmetro de colmo, não ocorreu resposta às doses de $\mathrm{N}$ aplicado em cobertura, e também aos híbridos. Já para Farinelli \& Lemos (2010), foi verificado que o nitrogênio atuou no crescimento vegetativo, promovendo um acréscimo na altura

Tabela 3. Matéria seca do sistema radicular, altura de planta, altura de inserção da primeira espiga e diâmetro de colmo em função de doses de $\mathrm{N}$ em cobertura em dois híbridos de milho na safrinha.

\begin{tabular}{|c|c|c|c|c|}
\hline \multirow[t]{2}{*}{ Tratamentos } & \multirow{2}{*}{$\begin{array}{c}\text { Matéria seca do } \\
\text { sistema radicular } \\
\left(\mathrm{g} \mathrm{planta}^{-1}\right)\end{array}$} & Altura de planta & $\begin{array}{c}\text { Altura de } \\
\text { primeira espiga }\end{array}$ & $\begin{array}{c}\text { Diâmetro de } \\
\text { colmo }\end{array}$ \\
\hline & & \multicolumn{3}{|c|}{ } \\
\hline \multicolumn{5}{|c|}{ Doses de $\mathrm{N}$ em cobertura (D) } \\
\hline 0 & $130,6^{(1)}$ & 170,3 & 82,1 & 1,6 \\
\hline 30 & 137,5 & 165,3 & 83,8 & 1,8 \\
\hline 60 & 153,7 & 178,6 & 84,7 & 1,8 \\
\hline 90 & 212,3 & 183,1 & 87,2 & 1,9 \\
\hline Teste F & $8,25^{*}$ & $1,53^{\mathrm{ns}}$ & $0,15^{\mathrm{ns}}$ & $3,53^{\mathrm{ns}}$ \\
\hline CV (\%) & 26,04 & 3,05 & 4,58 & 5,69 \\
\hline \multicolumn{5}{|l|}{ Híbridos $(\mathrm{H})$} \\
\hline BM 207 & 158,2 & $162,3 \mathrm{~b}$ & $72,2 b$ & 1,7 \\
\hline DKB 390 PRO2 & 158,5 & $191,4 \mathrm{a}$ & 95,8 a & 1,8 \\
\hline Teste F & $0,001^{\mathrm{ns}}$ & $45,13^{* *}$ & $17,90^{*}$ & $0,09^{\text {ns }}$ \\
\hline $\mathrm{CV}(\%)$ & 23,05 & 6,93 & 17,89 & 11,32 \\
\hline \multicolumn{5}{|l|}{$\mathrm{D} \times \mathrm{H}$} \\
\hline Teste F & $0,13^{\mathrm{ns}}$ & $0,15^{\mathrm{ns}}$ & $3,41^{\mathrm{ns}}$ & $0,73^{\mathrm{ns}}$ \\
\hline Média & 158,4 & 176,8 & 84,5 & 1,8 \\
\hline
\end{tabular}

Médias seguidas de letras distintas diferem entre si pelo teste de Tukey a $5 \%$ de probabilidade. **significativo a $1 \%$; *significativo a $5 \%$; ${ }^{\text {ns }}$ não significativo; ${ }^{(1)} \mathrm{y}=0,87 \mathrm{x}+119,4$ e $\mathrm{R}^{2}=0,82 *$. 
de plantas, na altura de espiga e no diâmetro do colmo.

Na Tabela 4, nota-se que não ocorreu efeito significativo para o número de grãos por espiga e fileiras por espiga em relação às doses de $\mathrm{N}$ em cobertura, corroborando os dados obtidos por Souza et al. (2012). Contudo, ocorreu diferença para esses dois componentes da produção em relação aos híbridos semeados, com superioridade para o DKB 390 PRO2 (Tabela 4). Esses componentes da produção podem afetar positivamente a produtividade de grãos, o que foi obtido neste experimento (Tabela 5).

Em relação à massa de 100 grãos, ocorreu novamente superioridade para o híbrido transgênico, com acréscimo das doses de $\mathrm{N}$ aplicado (Tabela 5). No trabalho efetuado por Soratto et al. (2010), a massa de grãos também foi aumentada pela aplicação de doses de $\mathrm{N}$, porém até a dose máxima estimada de $78,5 \mathrm{~kg} \mathrm{ha}^{-1}$.

Quanto à produtividade de grãos, houve efeito em todos os tratamentos, tendo acréscimo linear das doses de N, maior valor para o DKB 390 PRO2, e interação significativa para esses tratamentos (Tabela 5).

Kappes et al. (2009) verificaram que a aplicação de nitrogênio influencia, positivamente, o desempenho produtivo do milho, na segunda safra em sucessão à soja. O mesmo aumento linear foi observado por Soratto et al. (2010) nas doses de $0,30,60,90$ e $120 \mathrm{~kg} \mathrm{ha}^{-1}$ de N. Souza et al. (2012) observaram aumento na produtividade de grãos de milho safrinha até a dose $150 \mathrm{~kg} \mathrm{ha}^{-1} \mathrm{de} \mathrm{N}$, contudo quando cultivado após milho verão. Já para Góes et al. (2012), a produtividade não foi influenciada pelas fontes (ureia e sulfato de amônio) e doses de nitrogênio em cobertura $\left(0\right.$ a $\left.80 \mathrm{~kg} \mathrm{ha}^{-1}\right)$.

A produtividade teve diferença, sendo significativa a $1 \%$ somente entre os híbridos testados, em que o DKB 390 PRO2 foi superior ao BM 207 com

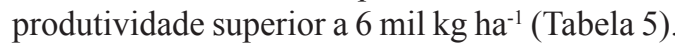

O BM 207 não foi responsivo à adubação nitrogenada em cobertura. Nota-se que, a maior dose de $\mathrm{N}$ aplicado não foi suficiente para atingir a máxima produtividade de grãos para o DKB 390 PRO2 (Figura 1). Por meio das equações de regressão, pode-se observar que a produtividade de grãos respondeu de forma quadrática às doses de nitrogênio para esse híbrido transgênico. O máximo rendimento estimado de grãos foi $7.358 \mathrm{~kg} \mathrm{ha}^{-1}$, obtido com $74,4 \mathrm{~kg} \mathrm{ha}^{-1}$ de $\mathrm{N}$ em cobertura. Contudo, as doses de $\mathrm{N}$ estudadas estão de acordo com as recomendações de Souza et al. (2003), Kappes et al. (2009) e Soratto et al (2012), nas quais, para altas produtividades, as

Tabela 4. Número de espigas por planta, fileiras por espiga e grãos por espiga em função de doses de $\mathrm{N}$ em cobertura em dois híbridos de milho na safrinha.

\begin{tabular}{|c|c|c|}
\hline \multirow[t]{2}{*}{ Tratamentos } & $\begin{array}{c}\text { Fileiras por } \\
\text { espiga }\end{array}$ & Grãos por espiga \\
\hline & \multicolumn{2}{|c|}{ - } \\
\hline \multicolumn{3}{|l|}{ Doses de $\mathrm{N}$ em cobertura (D) } \\
\hline 0 & 15,0 & $342^{(1)}$ \\
\hline 30 & 15,0 & 383 \\
\hline 60 & 15,0 & 389 \\
\hline 90 & 16,0 & 419 \\
\hline Teste F & $2,04^{\mathrm{ns}}$ & $2,48^{\mathrm{ns}}$ \\
\hline $\mathrm{CV}(\%)$ & 6,61 & 11,24 \\
\hline \multicolumn{3}{|l|}{ Híbridos $(\mathrm{H})$} \\
\hline BM 207 & $14,0 \mathrm{~b}$ & $342 \mathrm{~b}$ \\
\hline DKB 390 PRO2 & $16,0 \mathrm{a}$ & $424 \mathrm{a}$ \\
\hline Teste F & $37,96^{* *}$ & $16,29^{*}$ \\
\hline CV (\%) & 6,53 & 15,03 \\
\hline \multicolumn{3}{|l|}{$\mathrm{D} \times \mathrm{H}$} \\
\hline Teste F & $1,08^{\mathrm{ns}}$ & $0,36^{\mathrm{ns}}$ \\
\hline Média & 15,0 & 383,0 \\
\hline
\end{tabular}

Médias seguidas de letras distintas diferem entre si pelo teste de Tukey a 5\% de probabilidade. **significativo a $1 \%$; *significativo a $5 \%$; ${ }^{\text {ns }}$ não significativo; ${ }^{(1)} \mathrm{y}=0,79 \mathrm{x}+347$ e $\mathrm{R}^{2}=0,93 *$. 
Tabela 5. Massa de 100 grãos e produtividade de grãos em função de doses de $\mathrm{N}$ em cobertura em dois híbridos de milho na safrinha.

\begin{tabular}{|c|c|c|}
\hline Tratamentos & $\begin{array}{c}\text { Massa de } 100 \text { grãos } \\
\text { (g) }\end{array}$ & $\begin{array}{c}\text { Produtividade de grãos } \\
\qquad\left(\mathrm{kg} \mathrm{ha}^{-1}\right)\end{array}$ \\
\hline \multicolumn{3}{|l|}{ Doses de N em cobertura (D) } \\
\hline Testemunha & $26,2^{(1)}$ & $4.467^{(2)}$ \\
\hline 30 & 27,8 & 5.674 \\
\hline 60 & 32,0 & 5.387 \\
\hline 90 & 29,7 & 6.147 \\
\hline Teste F & $8,04^{*}$ & $6,75^{*}$ \\
\hline $\mathrm{CV}(\%)$ & 7,43 & 12,97 \\
\hline \multicolumn{3}{|l|}{ Híbridos $(\mathrm{H})$} \\
\hline BM 207 & $25,5 \mathrm{~b}$ & $4.313 \mathrm{~b}$ \\
\hline DKB 390 PRO2 & $32,3 \mathrm{a}$ & $6.525 \mathrm{a}$ \\
\hline Teste F & $50,40^{* *}$ & $65,99^{* *}$ \\
\hline CV $(\%)$ & 8,63 & 14,21 \\
\hline \multicolumn{3}{|l|}{$\mathrm{D} \times \mathrm{H}$} \\
\hline Teste F & $0,91^{\text {ns }}$ & $2,96 *$ \\
\hline Média & 28,9 & 5.419 \\
\hline
\end{tabular}

Médias seguidas de letras distintas diferem entre si pelo teste de Tukey a $5 \%$ de probabilidade. ** significativo a $1 \%$; *significativo a $5 \%$; ${ }^{\text {ns }}$ não significativo; ${ }^{(1)} \mathrm{y}=0,049 \mathrm{x}+26,7$ e $\mathrm{R}^{2}=0,58^{*} ;{ }^{(2)} \mathrm{y}=15,84 \mathrm{x}+4.706$ e $\mathrm{R}^{2}=0,75^{*}$.

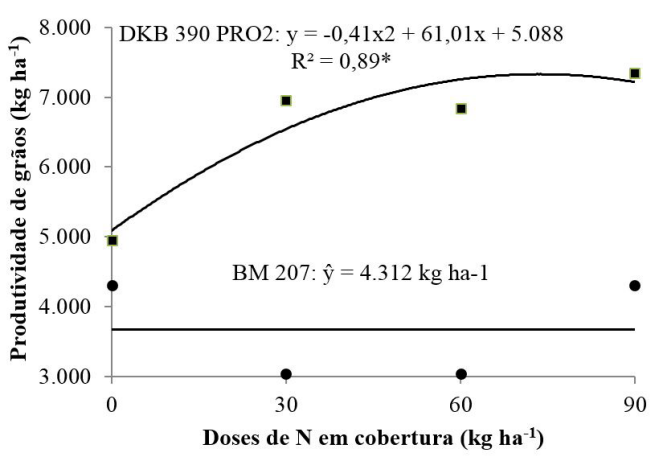

Figura 1. Produtividade de grãos de milho em função de doses de $\mathrm{N}$ em cobertura em dois híbridos.

quantidades variam de 50 a $90 \mathrm{~kg} \mathrm{ha}^{-1}$ de $\mathrm{N}$ em cultivo de sequeiro.

A resposta da produtividade à adubação nitrogenada em cobertura depende de vários fatores, como umidade do solo, genética da planta e dose utilizada. Talvez o uso de doses maiores ou de outro híbrido possibilitasse efeito significativo na produtividade de grãos.

Quanto à eficiência agronômica de uso de nitrogênio (quantidade de $\mathrm{kg}$ de grãos de milho produzidos por $\mathrm{kg}$ de $\mathrm{N}$ aplicado), verifica-se maior incremento e maior ganho significativo para o híbrido DKB 390 PRO2 em relação às doses de $\mathrm{N}$ aplicado, quando comparado ao BM 207 (Tabela 6).
Tabela 6. Eficiência agronômica ${ }^{(1)}$ de híbridos de milho na safrinha em função de doses de $\mathrm{N}$ em cobertura. Barretos-SP, 2015.

\begin{tabular}{cccc}
\hline $\begin{array}{c}\text { Doses de N em } \\
\text { cobertura }\end{array}$ & & BM 207 & $\begin{array}{c}\text { DKB 390 } \\
\text { PRO2 }\end{array}$ \\
\cline { 1 - 1 } \cline { 4 - 4 } kg ha $^{-1}$ & & $----------\mathbf{~ k g ~ k g}^{-1}$ & ---------- \\
\hline 0 & & - & - \\
30 & & 55,1 & 116,9 \\
60 & & 3,5 & 126,2 \\
90 & & 42,8 & 106,6 \\
\hline
\end{tabular}

(1)Eficiência agronômica: $\mathrm{kg}$ de grãos de milho produzido por kg de $\mathrm{N}$ aplicado.

Aplicando-se de 30 a $60 \mathrm{~kg} \mathrm{ha}^{-1}$ de $\mathrm{N}$ em cobertura, no estádio $\mathrm{V}_{8}$, houve aumento na produção de grãos de milho, de 116,9 a 126,2 kg, para o híbrido transgênico, o que demonstra ser um material responsivo à adubação e, consequentemente, aos tratos culturais mais tecnificados.

Além dessas características, o N é o elemento que causa maiores efeitos no aumento de produção da cultura do milho. Além do seu efeito sobre a produtividade, o $\mathrm{N}$ interfere em diversas outras características da planta relacionadas ao crescimento e desenvolvimento, as quais, direta ou indiretamente, afetam a produtividade da cultura.

É importante relatar que a tecnologia YieldGard ${ }^{\circledR}$ VTPRO, lançada em 2011, tem potencial para um incremento de $4 \%$ de produtividade em relação 
às tecnologias de primeira geração (YieldGard ${ }^{\circledR}$ ), que têm proporcionado aumento de produtividade da ordem de $7 \%$ em comparação ao milho convencional. De acordo com informações do setor, a tecnologia do milho $\mathrm{Bt}$ faz com que os produtores rurais tenham aumento de $5 \%$ na produtividade e economizem $50 \%$ em inseticidas (SEMENTES AGROCERES, 2012). No entanto, no respectivo trabalho, o híbrido transgênico foi superior em $30 \%$ ao convencional e ainda não foi necessária a pulverização para o controle das lagartas.

\section{Conclusão}

A adubação nitrogenada influenciou positivamente na formação das raízes, massa de 100 grãos e produtividade de grãos.

O híbrido DKB 390 PRO2 respondeu às doses de $\mathrm{N}$ em cobertura, com maior produtividade de grãos obtida na dose de $74,4 \mathrm{~kg} \mathrm{ha}^{-1}$.

Os maiores incrementos e ganhos significativos de grãos foram estabelecidos para o híbrido DKB 390 PRO2 em relação às doses de $\mathrm{N}$ aplicadas, quando comparado ao BM 207.

\section{Referências}

AMARAL FILHO, J. P. et al. Espaçamento, densidade populacional e adubação nitrogenada na cultura do milho. Revista Brasileira de Ciência do Solo, v. 29, p. 467-473, 2005.

CASAGRANDE, J. R. R.; FORNASIERI FILHO, D. F. Adubação nitrogenada na cultura do milho safrinha. Pesquisa Agropecuária Brasileira, v. 37, n. 1, p. 33-40, 2002.

CRUZ, J. C.; PEREIRA FILHO, I. A.; SILVA, G. H. Milho - cultivares para 2012/2013. 2013. Disponível em: <http: www.cnpms.embrapa. br $>$. Acesso em: 20 nov. 2013.

FAGERIA, N. K.; BALIGAR, V. C. Enhancing nitrogen use efficiency in crop plants. Advances in Agronomy, v. 88, n. 1, p. 97-185, 2005.

FARINELLI, R.; LEMOS, L. B. Produtividade e eficiência agronômica do milho em função da adubação nitrogenada e manejos do solo. Revista Brasileira de Milho e Sorgo, v. 9, n. 2, p. 29-40, 2010.

FERREIRA, D. SISVAR software: versão 5.3. Lavras: DEX/UFLA, 2011. Software.
FORNASIERI FILHO, D. Manual da cultura do milho. Jaboticabal: Funep, 2007. 576 p.

GOES, R. J. et al. Nitrogênio em cobertura para o milho (zea mays 1.) em sistema plantio direto na safrinha. Revista Brasileira de Milho e Sorgo, v. 11, n. 2, p. 169-177, 2012.

KAPPES, C. et al. Influência do nitrogênio no desempenho produtivo do milho cultivado na segunda safra em sucessão à soja. Pesquisa Agropecuária Tropical, v. 39, n. 3, p. 251-259, 2009.

MAR, G. D. et al. Produção do milho safrinha em função de doses e épocas de aplicação de nitrogênio. Bragantia, v. 62, n. 2, p. 267-274, 2003.

RITCHIE, S. W.; HANWAY, J. J.; BENSON, G. O. Como a planta de milho se desenvolve. Piracicaba, 2003. ((Informações Agronômicas, 103).

SEMENTES AGROCERES. Biotecnologia. 2012. Disponível em: $<$ http://www.sementesagroceres. com.br>. Acesso em: 20 de nov. 2012.

SORATTO, R. P. et al. Fontes alternativas e doses de nitrogênio no milho safrinha em sucessão à soja. Revista Ciência Agronômica, v. 41, n. 4, p. 511-518, 2010.

SORATTO, R. P. et al. Parcelamento de fontes alternativas de nitrogênio no milho safrinha em sucessão à soja. Cientifica, v. 40, n. 2, p. 179 188, 2012.

SOUZA, J. A. et al. ARF. O. Adubação nitrogenada na cultura do milho safrinha irrigado em plantio direto. Bragantia, v. 70, n. 2, p. 447-454, 2012.

SOUZA, L. C. F. et al. Culturas antecessoras e adubação nitrogenada na produtividade de milho em plantio direto irrigado. Revista Brasileira de Milho e Sorgo, v. 2, p. 55-62, 2003.

SOUZA, E. F. C.; SORATTO, R. P. Efeito de fontes e doses de nitrogênio em cobertura, no milho safrinha, em plantio direto. Revista Brasileira de Milho e Sorgo, v. 5, n. 3, p. 395-405, 2006. 